\title{
HEMIDESMOSOMES IN AGEING SKIN
}

Lenka Suchá', Petra Čubáková , Lenka Machková', Iva Dolečková'

Contipro a.s., Dolni Dobrouč, Czech Republic

2 Department of Chemistry, Biochemistry and Biophysics, Institute of Pharmaceutical Chemistry University of Veterinary Medicine and Pharmacy in Košice, Košice, Slovak Republic

\section{INTRODUCTION}

Hemidesmosomes (Scheme I) are the specialized protein complexes present in the basement membrane, where they help to attach the epidermal cells to basal lamina. They are the key components ensuring skin integrity and thus, they contribute to the maintaining of the skin homeostasis. They consist of several distinct proteins, such as a and $\beta$ integrins, CD151, plectin, collagen 17Al and dystonin. During skin ageing and photoageing, the number of hemidesmosomes decreases. Therefore, the skin barrier function impairs and the skin become more fragile ${ }^{1,2}$. However, no study evaluating the hemidesmosomal proteins levels during ageing has been carried out so far.

\section{MATERIALS AND METHODS}

In this study, we compared the expression of the six major hemidesmosomal proteins between young and old skin. We examined the samples of the human skin biopsies obtained from young ( $n=8,5-9$ years, earlobes) and old ( $n=8,47-$ 63 years, eyelids) donors undergoing cosmetic surgery. We assessed the gene expression of the hemidesmosomal proteins by quantitative real-time RT-PCR and the level of the respective proteins immunohistochemically.

\section{RESULTS}

Thegeneexpression of the fivehemidesmosomal proteins (dystonin, plectin, collagen 17Al, a and $\beta$ integrins) was found to be significantly decreased in old skin in comparison with young skin. Except collagen 17Al, the reduction of the hemidesmosomal proteins level was also demonstrated in the immunohistochemically stained old skin samples.

\section{CONCLUSION}

In conclusion, we demonstrated the decrease in the hemidesmosomal proteins in aged skin. These changes could be related to the impaired skin barrier function and the fragility of the aged skin.

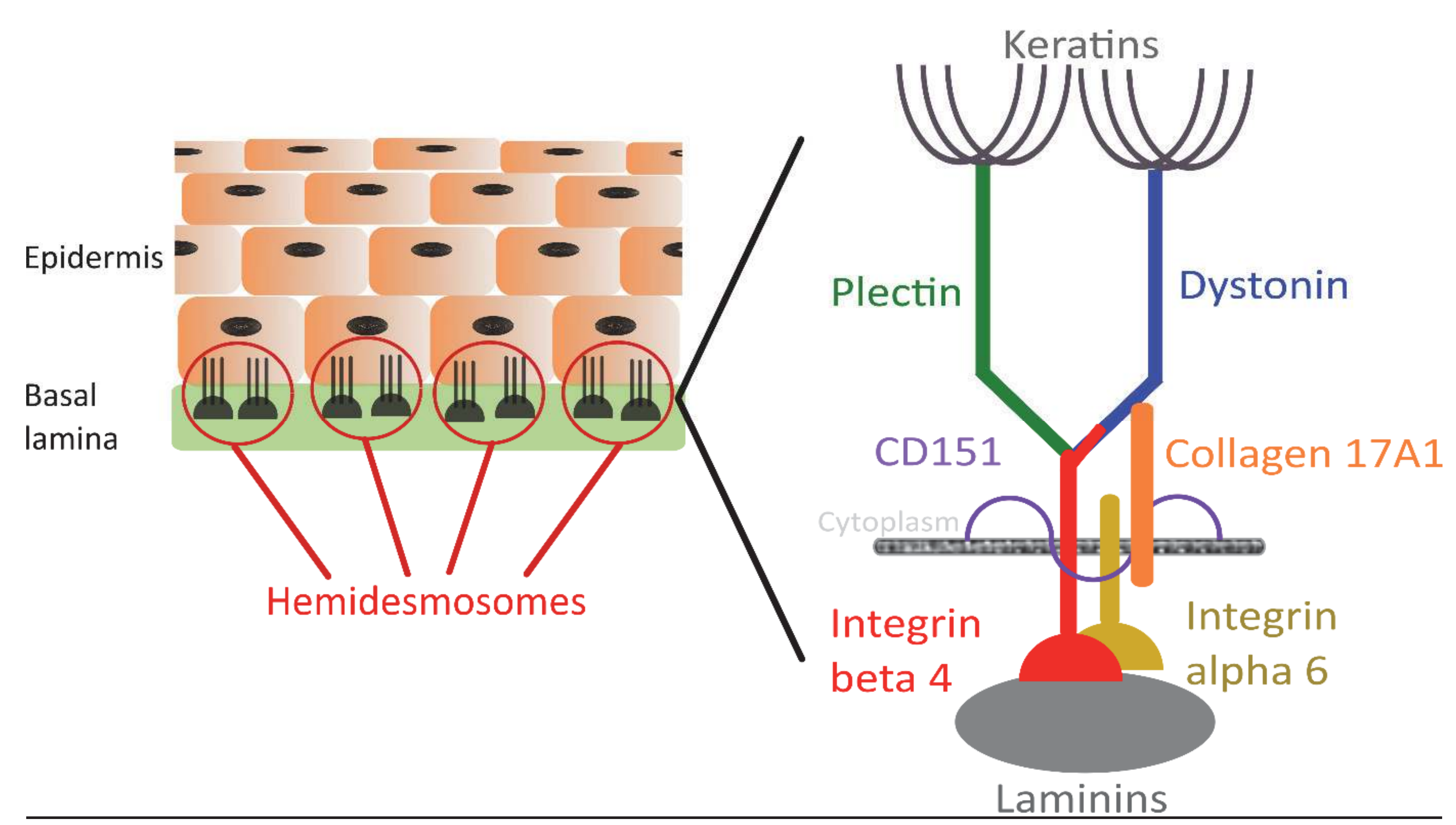

Scheme 1 Structure of hemidesmosomes in the skin.

GENE EXPRESSION OF HEMIDESMOSOMAL PROTEINS DECREASES WITH AGE

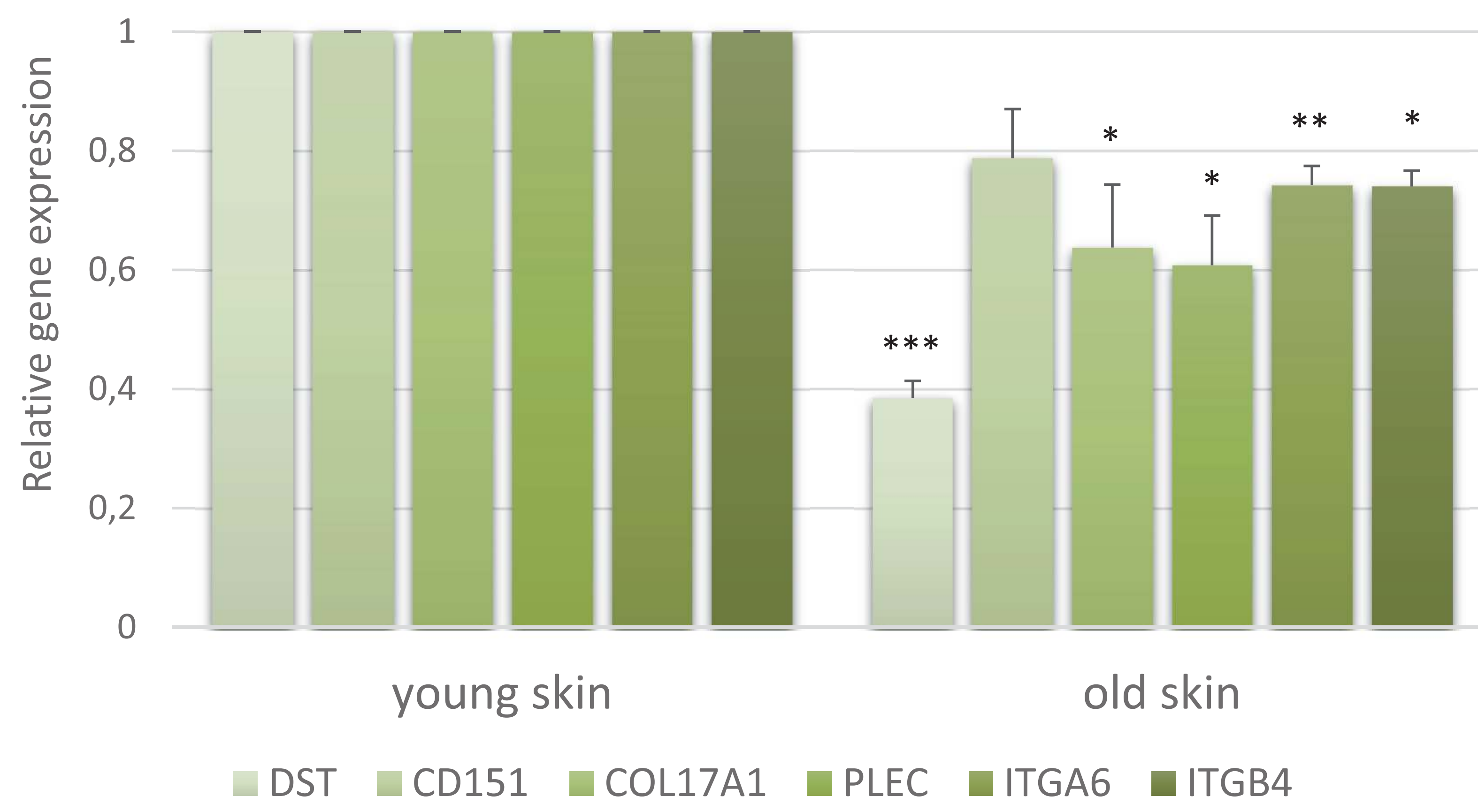

Figure 1. Gene expression of hemidesmosomal proteins in young and old skin. The gene expression was determined using quantitative RT-PCR. The values represent means \pm SEM of the gene expression of hemidesmosomal proteins in skin samples from 8 donors for each group $\left({ }^{\star} p \leq 0.05,{ }^{\star *} p \leq 0.01,{ }^{\star * *} p \leq\right.$ 0.001 compared to young donors, $n=4$ ).

The LEVEL OF HEMIDESMOSOMAL PROTEINS DECREASES WITH AGE

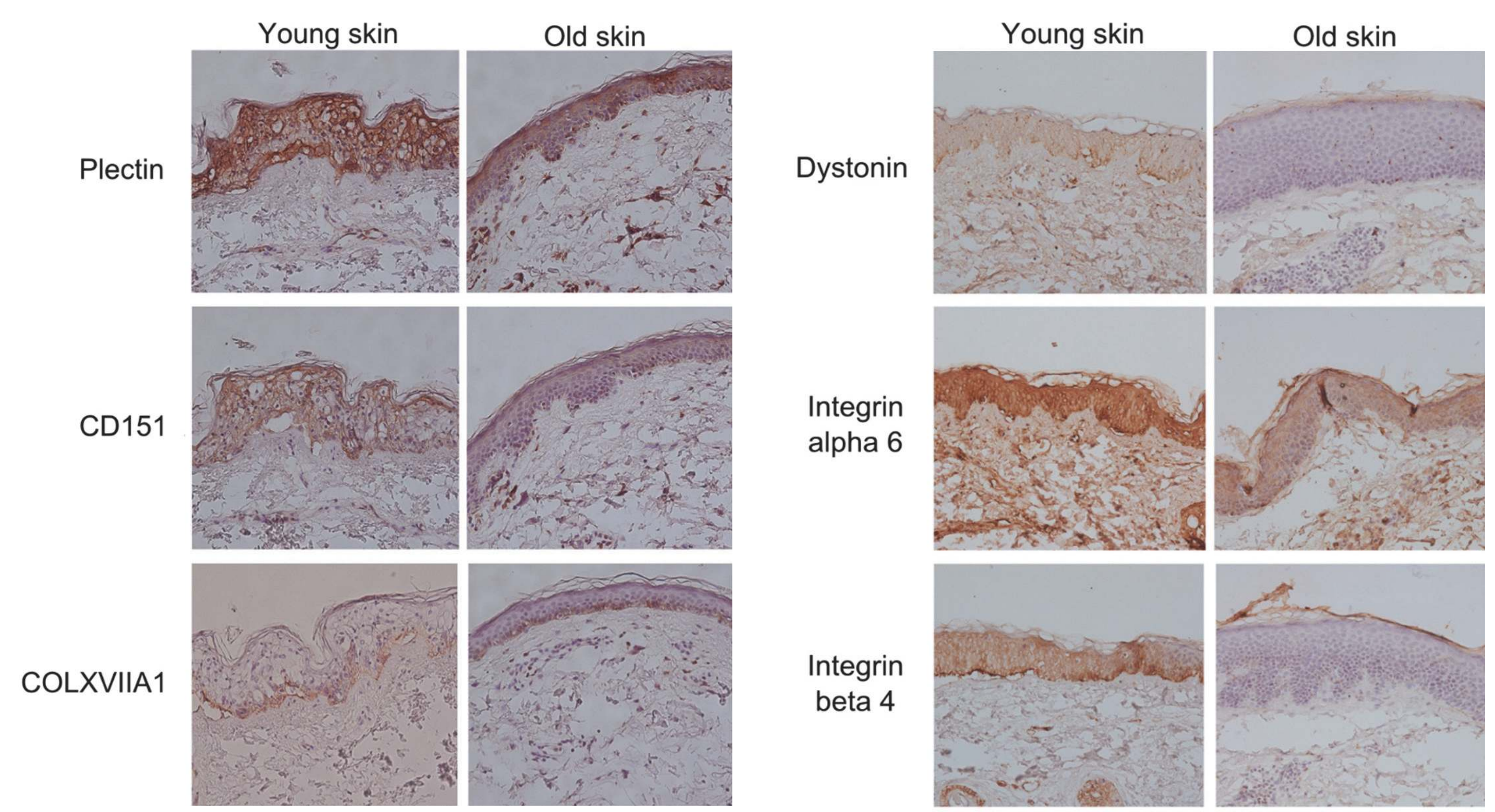

Figure 2. The immunohistochemical staining of hemidesmosomal proteins in the young and old skin. The representative image (magnification 20x).

\section{REFERENCES}

Varlet et al. Age-related functional and structural changes in human dermo-epidermal junction components. J Investig Dermatol Symp Proc. 1998;3(2):172-9.

2. Amano S. Possible involvement of basement membrane damage in skin photoaging. J Investig Dermatol Symp Proc. 2009;14(1):2-7. 